Portland State University

PDXScholar

Understanding Women in Prison: a Review of Gender Specific Needs and Risk Assessments and their Policy and Research Implications

Elise Barlow

Portland State University

Follow this and additional works at: https://pdxscholar.library.pdx.edu/honorstheses

Let us know how access to this document benefits you.

Recommended Citation

Barlow, Elise, "Understanding Women in Prison: a Review of Gender Specific Needs and Risk Assessments and their Policy and Research Implications" (2014). University Honors Theses. Paper 79. https://doi.org/10.15760/honors.46

This Thesis is brought to you for free and open access. It has been accepted for inclusion in University Honors Theses by an authorized administrator of PDXScholar. Please contact us if we can make this document more accessible: pdxscholar@pdx.edu. 


\title{
Understanding Women in Prison: A Review of Gender Specific Needs and Risk Assessments and their Policy and Research Implications
}

\author{
by \\ Elise Barlow \\ An undergraduate honors thesis submitted in partial ful $\square$ llment of the \\ requirements for the degree of \\ Bachelor of Arts \\ in \\ University Honors \\ and \\ Sociology \\ Thesis Adviser \\ Randy Blazak
}

Portland State University

2014 


\begin{abstract}
In the last 30 years, the number of women in the criminal justice system has risen significantly, yet the criminal justice system still bases much of its policy on empirical research conducted using a majority of male subjects. Risk and need assessments, which are generally used to categorize inmates into varying risk levels to lower recidivism, have been faulted by many feminist scholars for having little pertinence for women. Their lack of gender sensitive factors has left many scholars questioning their validity. Available correctional programs are based on the knowledge collected by these "gender neutral" assessments. Therefore, female offenders are not receiving rehabilitation that is relevant to their lives. This paper examines the context of female offenders, the theoretical framework of criminality and gender, the current understanding of gender specific needs, and the application of Risk and need assessments, specifically the LSI-R (Levels of Service Inventory-Revised), and their consequences. Although there is some overlap between the factors that predict recidivism of men and women, the lack of data specifically to women has resulted in a lack or resources for women. This paper concludes with suggestions for further research into the risk levels and assessments and changing correctional policy in order to distribute resources to better serve the needs of women.
\end{abstract}

\title{
Introduction: The Gendered Effects of Public Policy
}

Overflowing prisons, a weakened and overburdened foster care system, communities broken by the constant recidivism of their members- these are the fruits of mass incarceration. Beginning in the 1980's, rates of incarceration in the United States started to increase slowly. By the end of the 90's, this increase was nothing less than exponential. Currently, America has incarcerated more of its population than any other country in the world, imprisoning about 1 in every 35 adults.

The War on Drugs, which began its rampage in the 80 's, is one major cause for the rise in incarceration. Mandatory sentencing was implemented for minor drug offenses, with the number of incarcerated individuals skyrocketing as result. The increased severity on drug related crimes proved to have gendered effects. 
During the last 30 years, the increase in the incarceration of women was 1.5 times that of men (The Sentencing Project). According to the Federal Bureau of Prisons, over $60 \%$ of the women in their custody are serving sentences for drug offenses (Covington 2008). The typical female offender is a poor, uneducated African American, who is likely on welfare and the sole caretaker of minor children (Bloom et al. 2003). The imprisonment of these women presents a major social problem, as it puts pressure on the social services and traumatizes the children they leave behind (White 2012). The graph below is a visual representation of the 856\% increase of women in state and federal prisons between 1980-2012.

\section{Number of Women in State and Federal Prisons, 1980-2012}

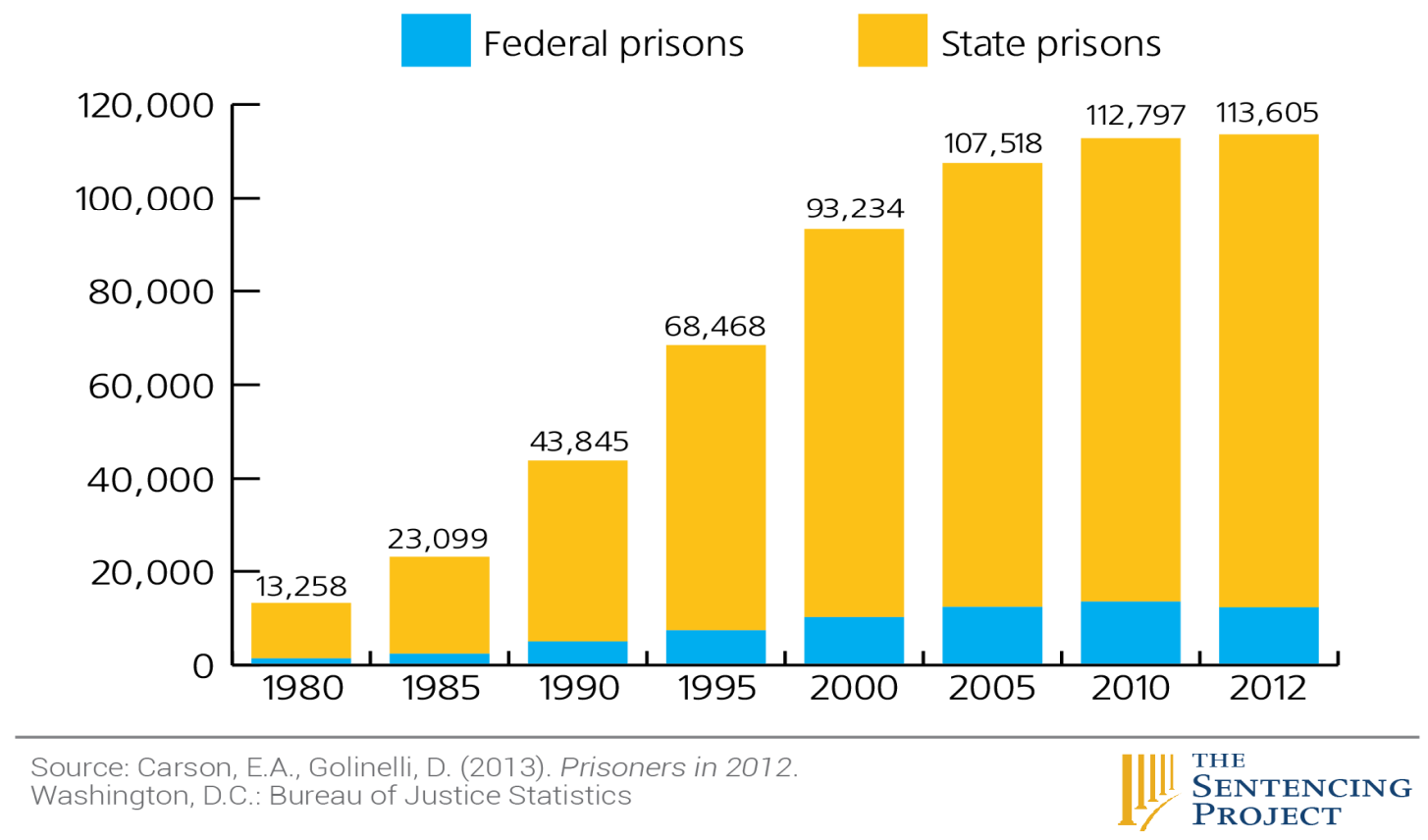

Although this unprecedented rise was seen in both genders, between 2000 and 2010 the female arrest rate increased by $29 \%$, while the number of men arrested increased by only 7\% (Bureau of Justice Statistics 2011). While the number of 
women in correctional settings has substantially increased, the institution of criminal justice continues to ignore the context of these women's lives and the reality of their needs. Correctional policy claims a gender-neutral stance, ignoring the psychological and social literature differentiating men and women's criminological pathways. The misinformed nature of the criminal justice system has only exacerbated the problem of mass incarceration of women.

Risk and needs assessments are used within all levels of corrections, from courts to community supervision, thus having consequences for inmates during prison as well as after release. Assessment tools are the base line for almost all decisions made for an individual's rehabilitation. Reducing recidivism, an important part of correctional policy, is also a crucial goal of risk assessments. Meta analytic studies, although flawed in their population demographic, still claim that the risks of recidivism they have determined are universal. Programs that attempt to incorporate gender specific needs receive less funding because of they stray from the conventional gender-neutral model (Voohris 2010). The quality of the background research determines the validity of an assessment tool, yet these tests are based on studies conducted on majority male populations. Currently, these assessment tools are being applied arbitrarily to female offenders, regardless of their general exclusion from the empirical data. The risk levels of recidivism (low, medium, and high) determined by these tests are applied to women without a solid base of valid evidence. Without incorporating gender sensitive needs, classification systems are in danger of over-classifying women, 
and neglect the most important risk factors and needs relevant to female offenders (Voohris 2010).

Agnew's General Strain Theory (GST), Kathleen Daly's Pathways Theory, Relational theory, as well as emerging literature on gender specific needs will be the backbone to understanding the impact of risk assessment measures that ignore gender and how needs specific to gender could rectify their failure. Within the broader body of literature, there is little agreement on the use of risk assessments. Many contemporary studies have found that risk assessments have some predictive validity for women, however this paper intends to show that the addition of gender sensitive needs produces a much higher rate of predictive validity. More importantly, these studies have pointed to a bigger question- are men and women's risk levels even comparable given the their differentiating social circumstances? The conflict is indicative of a need for further study and a better understanding of the incorporation of gendered pathways into risk assessment. In summation, the goal of this paper is to bring forth awareness of the current state of women within the criminal justice system and to suggest that the solution lies in more research. Compiling this empirical data will bring us one step closer to help restore the damage that mass incarceration has wrought upon American society.

\section{Women and Crime: Theoretical \& Contextual Perspectives}


To begin this paper, it is important to note that these theories were chosen to represent a holistic picture on risk assessments. These theories span a few disciplines, between criminology, sociology and psychology. For the sake of this project, feminist theories were not discussed, although there are many feminist theories that would strengthen the conversation about risk assessment.

\section{General Strain Theory}

Developing gender sensitive risk assessments and programs in the correctional setting requires a theoretical understanding of the framework around female criminality. Women commit crime less often then men, and their entries into criminal behavior tend to be very different. The focus then falls on the context of the crime, rather than the quantitative analysis. Understanding the difference between women and men's pathways into crime is pertinent to understanding how to rehabilitate them.

Robert Agnew's general strain theory helps unravel the complexity of female offending. Agnew's strain theory, an expanded and more inclusive version of Robert Merton's strain theory, explains that criminal behavior rises in association with several types of social strain. While Merton's strain theory indicated that deviancy comes from the inability to achieve societal goals, like monetary success, Agnew instead casts a wider net to include emotional, cognitive, and behavioral strains (Agnew 1992). In a more recent work, Agnew et al. conducted a study to understand how GST (General Strain Theory) explained the differences in male and female criminal behavior. This study, not intended to unravel why women commit less crime, rather focused on the different strains 
that were ubiquitous in the lives of each gender. In regard to female criminality,

Agnew et al. ties the act of crime with the omnipresent force of societal oppression in women's lives.

Women's oppression in various social arenas may play an important role in the generation of strain, and ultimately criminal behavior. In the preceding discussion, we argued that the following types of strain may be especially conductive to crime among females: the failure to achieve financial and interpersonal expectations; the failure to be treated in a just and fair manner by others, including family members, intimate others, and employers; the loss of positive ties to others; a broad range of restrictions on behavior...the experience of emotional, physical, and sexual abuse; the role-related strains often associated with "pink-collar" jobs and the housewife role (Agnew et al. 1997)

The strain that men are facing, according to Agnew, promotes a more violent and serious appearance, while female crime is displayed through internalizing the oppression placed upon them. Using literature on gender and stress, Agnew et al. points out women are more likely to internalize their strain, committing nonviolent crimes, such as substance abuse. This in turn can lead to property crimes to support drug habits. The strain of being a designated 'minority' group displays itself in a different delinquent pattern than those that have more privilege, which explains the difference between men and women. Mauer, Potler, and Wolf (1999) conducted research that also supports these finding. In their study on the effects of drug war policy on women, they found that a third of the rise in male incarceration was attributed to drugs, while half of female incarceration was. Although drugs play a significant role for both genders, the context of women's lives leads them to these negative behaviors in a different 
way. Women, because of their status in society, often struggle on the periphery of the economic mainstream. This means less access to legitimate ways to not only make money, but also to cope with the stress.

Traditionally, and GST also supports this, women commit less crime than men. However, with the changing policy around drug use, more women are beginning to feel the stigmatizing effects of the social label 'criminal'. The War on Drugs meant shifting focus from big time drug organizations to street level dealers (Bush-Baskette 2000). It also meant a shift from treatment to punishment (Bloom et al. 2004). Substance abuse became a problem of the criminal justice system, rather than one of public health. Women generally are more involved with lowlevel dealing and drug use than top-level distribution (Bush-Baskette 2000). This meant as the focus shifted, so did the demographics of prisons in the US. According to GST, strain upon women, especially those of a lower social economic status, increased dramatically during and after the inception of the War on drugs. A few policy initiatives also played a part in increasing levels of strain, especially reforms that contributed to the dismantling of the welfare system. In 1996, "Temporary Assistance for Needy Families" or TANF, was passed. This reform was implemented to remove any access to welfare benefits from those convicted of a drug felony (Bloom et al. 2004). This lifetime welfare ban has a disproportionate effect on women, especially women of color. Minority women are highly susceptible to poverty, because of the institutionalized racism in the United States. Therefore they are overrepresented in the welfare system (Allard 2002; Bloom et al. 2004) and consequentially bear a higher portion of the burden of poverty. 
Demographics in the correctional community also support this, as 1 in every 19 African-American women are estimated to be imprisoned, compared to 1 in every 118 white women (The Sentencing Project, 2012) The intersectionality of race, class, and gender creates omnipresent strain, and, as GST would contend, has high probability of leading to crime.

\section{Gendered Pathways}

A second important theory in female criminality is that of Kathleen Daly's (1992) work on the pathways of women. This framework is important not only because it explains gender differences in crime, but also differences within women. Based on a 34 participant qualitative sample, her work illustrates the mechanisms of survival seen in most female offenders. Although a small sample, this work deserves attention, as it has be shown to be valid within gender specific literature (Bloom et al. 2003). Daly (1992) created five differing pathways that women follow to crime.

Street women: This indicates women or girls fleeing from abuse and violence and entering street life. The crimes that follow may be drug use, prostitution, or property crimes.

Drug Connected Women: Women who are using drugs may be coerced by intimate partners or family members to traffic drugs.

Harmed and Harming Women: Serious child abuse, involving either physical or sexual, and/or neglect causing a lifetime of criminal behavior. 
Battered Women: Women who are abused by intimate partners, but are unlikely to have committed crime prior to the abuse. The crime that follows is geared towards coping and survival.

Economic Offending: These women can be separated into two categoriespoor women offending for survival, and women who commit crimes because of greed or social aspiration. The latter may have no history of abuse, addiction or violence. (Brennan et al. 2010; Daly 1992)

Most of the pathways above are motivated by survival. For the majority of female criminals, abuse and trauma are involved, making them a very different population from men (Bloom et al. 2003). These pathways represent the majority of female offenders and the reality of their lives. The application of this theory has been represented in many gender responsive studies and is extremely popular within the literature. The following sections on gender responsive factors will elaborate more on the application of pathways theory.

\section{Relational Theory}

Relational theory indicates that the state of women's relationships is often the driving force behind their criminal behavior (Covington et al.2006). Much of the basis of this theory is rooted in psychology, and therefore concentrates on the difference between male and female crime being in each of their distinguished forms of identity development. Jean Baker Miller, in her 1976 book Toward a New Psychology of Women, writes that the primary motivation in a woman's development is her connection to others. Continuing on this work, authors in the 
field of relational theory have developed three major concepts- cultural context, relationships, and pathways to growth (Kaplan 1984). Each distinguishes an important element in the woman's development. Cultural context implies the importance of the social environment that a woman develops in. The second, relationships, recognizes the importance of connections as the central organizing feature of a woman's development. The third, pathways to growth, indicates that the value women place on relationships is a strength and can lead to healthy fostering of identity (Covington 2007; Kaplan 1984). However, this can play out both positively and negatively. Women who develop positive relationships in their lives will be less likely to commit deviant acts in order to sustain these connections. However, for many in the criminal justice system, the opposite applies.

Understanding relational theory helps shape understanding of female criminality and how it differs from men. Because women are more attuned to relationships, their pathways into crime often revolve around negative relations, like abusive intimate partners. It could also arise from a lack of relationships, having many loved one die, or being abused at a young age (Covington 2007). Miller, in her later work (1990), coined the term "condemned isolation". This term refers to a situation in which a woman feels that she is the problem in her important relationships. This internalization of negative stimuli eften can lead to drug use and other self-destructive behaviors (Miller 1990). Children have a substantial effect on the female offender. $70 \%$ of women in prison have children, and more than half of these women never see their children while they are 
serving time (Bloom et al. 2003). The absence of relationships with their children, and the isolation of prison, can cause serious hindrances in a woman's rehabilitation. Behaviors such as negativism, manipulation, rule breaking, and fighting may be a sign of the grief and shame that women feel about the destruction of their roles as mothers (Covington 2007; Garcia Coll et al. 1998). In Garcia Coll et al.'s qualitative study on incarcerated mothers, the loss of connection with their children was often cited as the cause of relapse into crime. One mother stated, "I don't have my children, what will I do? I'll go back and to the drug again. I will go back to prostitution again. And I'll go back to prison again. Why fight? Why fight if I have nothing?" (Garcia Coll et al. 1998). Relational theory presents a framework of understanding for the importance of relationships in not only causing criminal behavior but also perhaps preventing it. Prisons can often exacerbate that problem by separating women from their children in a way that perpetuates damage already done by adverse social circumstances.

\section{Applying the Theory: Identified Gender Specific Needs}

Beginning in the 1980's, literature addressing the specific needs for women in prison moved to the forefront of academic concerns. Scholars began speaking up against the criminal justice system, pointing out that there was little evidence that the current rehabilitation philosophy could even apply to the female offender. As a consequence, particular needs have been identified as important to women. These factors represent the actuality of female offending, and, although there 
have not been a sufficient number of studies to confirm their connections to predicting recidivism their relevance to women's lives remains an important indicator that further studies need to be done.

Gender specific needs means identifying particular elements that are unique to women using theoretical frameworks and evidence based research. Due to current research and understanding, most in the field of corrections agree that women have different needs then men, but the solutions are seen are being the same. These needs are either "not typically seen in men, seen in men but occur at greater frequency in women, or occur in equal frequency among men and women but affect women in uniquely personal and social ways that should be reflect in current correctional assessment." (Voorhis et al. 2010). In this section, each need will be identified and explained.

\section{Trauma and Abuse}

As seen in the theoretical discussion, trauma and abuse play one of the most crucial factors in a woman's criminality and her recovery. Over $60 \%$ of women in prison reported having experienced physical or sexual violence, and most reported it occurring before the age of 18, according to the Bureau of Justice Statistics (1999). The rates of sexual abuse for women were also staggeringly high, at $23 \%-39 \%$. In comparison, incarcerated men only reported a $2 \%-6 \%$ rate of sexual abuse (Bureau of Justice Statistics, 1999). Other studies have found the rate much higher, around 75\%, which could be the consequence of underreporting (Owen \& Bloom 1995; Salisbury et al. 2009). The high discrepancy between men and women make this issue gender specific. Many 
studies have linked childhood abuse with criminality in adulthood, although studies have been inconclusive with connecting histories of abuse to the prediction of recidivism. Messina et al. (2014) found that trauma informed programs were far more likely to improve outcomes, specifically for women who had developed PTSD (Post Traumatic Stress Disorder). Although not all women who are abused develop PTSD, it is an incredibly common disorder among female offenders. Messina et al. concluded that trauma informed treatment should at the very least be researched as a beneficial possibility for female offenders. The magnitude at which female offenders experience abuse should be considered when developing tools for their successful rehabilitation.

\section{Mental Illness}

Within the prison system, $73 \%$ of women report having mental illness symptoms in comparison to 55\% of men (James et al. 2007). Females more often present with varying types of mood disorders, rather than antisocial personality disorders. Antisocial personality disorders are the subject of most cognitive restructuring programs in prison. What this means is programs within prison attempt to change criminal behaviors through addressing antisocial tendencies (Bloom et al. 2003) Since women do not often exhibit antisocial disorders, they often fail to receive cognitive thinking treatment that applies to them. The treatments for mood and anti-social disorders are different, as is the context that they develop in. Examples of mood disorders are depression and anxiety, both of which are far more prevalent among female offenders than male offenders (Voohris et al. 2010). These mood disorders often intersect, such as depression 
and substance abuse, at a much higher rate than men (Bloom et al. 2003). Mood disorders can often be over looked by the current assessment system.

...Traditional mental health domains on risk assessment instruments are driven largely by the offender's exhibition of severely psychotic behavior. Major mood disorders, such as those frequently seen with women, can be overlooked if they have not been previously diagnosed and recorded. (Salisbury et al. 2009)

Even though mood disorders have a significant impact on female recidivism, (Deschenes et al. 2007), lack of attention is given to them during assessment. Many women's disorders have been overlooked because they do not have a significant medical history. However, studies have shown that stress, anxiousness, fear, and/or suicidal thoughts or attempts are strong predictors of female recidivism (Benda et al. 2005).

\section{Self-Esteem \& Efficacy}

Gender responsive literature relates the idea of self-esteem closely to that of empowerment. Women entering and exiting the criminal justice system are incredibly disempowered. Women inherently have a lower status in society and adding a felony places them far below the average woman. Aside from the social stigma, their common histories riddled with abuse, addiction and negative relationships cause female offenders to lack the self-confidence to face a stigmatizing return to their communities (Wright et al. 2007). Unfortunately, analysis done on mostly male populations has shown that incorporating selfesteem has little effect on predicting recidivism and may actually have a negative effect on behavior (Andrews \& Bonta, 2003). Women may be a different story. 
Low self-esteem is often the product of abuse, mental illness, and a variation of other elements important to female offenders (Bloom et al. 2003). The general profile of a female offender is one who is disempowered- poor, in dysfunctional abusive relationships, and oppressed by a society unable to support her needs. Self esteem and efficacy refers also to financial empowerment, and creating a sense of control in ones life to complete certain goals (Salisbury et al 2009). Gender responsive assessments seek to incorporate financial and social empowerment to reduce recidivism.

Although literature is sparse on connecting self-efficacy to lower recidivism rates, literature does support the connection between successful treatment and gaining a sense of self-control (Task Force on Federally Sentenced Women, 1990). However, in order to achieve the goals of education and financial independence, women must first believe they can, and then society must believe as well. If incarceration is partially caused by inequality, then empowerment should be included in the answer.

\section{Dysfunctional Relationships}

Following the framework of relational theory, female offenders are highly influenced by the relationships in their life (Miller 1976). For most female offenders however, these relationships mostly present in the form of abuse or neglect. Often criminal behavior is derived from the need to maintain these dysfunctional relationships. When asked to commit criminal acts to secure a partner's needs, in the face of abandonment or abuse, these women will easily turn to criminal activity (Salisbury et al. 2009; Richie 1996). Unlike men, women 
often turn to crime to protect relationships in their life. Benda et al. (2005) in a study on the differences in male and female recidivism, found that living with a criminal partner is a statistically strong predictor of recidivism. Women who forged positive relationships, especially with a partner and kids, were far less likely to reoffend (Benda et al. 2005). However, like many other gender specific factors, more studies must be done to understand the effects of dysfunctional relationships.

\section{Parental Responsibilities}

The difference in parental responsibilities between men and women is perhaps one of the most apparent. Approximately two-thirds of women in prison have a child under the age of 18; almost all these women are the primary caretakers of their children, with only $25 \%$ having fathers around to take care of their children (Bloom et al. 2003). In contrast, 90\% of fathers in prison have mothers at home to take care of their children. Access to children is also incredibly limited, as more than half of all children never visit their mothers while they are in prison (Bloom et al. 2003). Those that are able to spend time with their mothers often do not view this as a positive experience.

Such issues as travel logistics, clearance processes, noise levels and distractions in visiting rooms, privacy, and the availability of toys or other child-friendly resources-any or all of which can have a profound impact on the visiting child's experience-are most often ignored. What should be an experience fostering family support and connection is instead an unpleasant or traumatic occasion for both the child and the mother (Covington 2007). 
Current policy structured around foster care is a central issue to incarcerated women. The Adoption and Safe Families Act of 1997 places a limit on the length a child can stay in foster care before a parental termination is filed (Mauer et al. 1999). The female offender will likely have her child taken away from her, causing incredible amounts of emotional distress for both the mother and the child. Ross et al. (2004) found that when a mother is threatened with the loss of her child, it is extremely likely that she will turn to crime. $85 \%$ of all maternal arrests occurred after placement of the child rather than prior. $56 \%$ of these mothers committed drug offenses (Ross et al. 2004). The stress of parenting (or loss of it), along side drug addiction and mental instability, are a precursor for female offending.

\section{Substance Abuse}

Substance abuse is considered one of the "central eight" risk/needs factors for both men and women (Andrews et al. 2006). Although men also present with high levels of addiction, women come to abuse illegal substances more often to cope with abuse and mental illness. The type of strain placed upon them is internalized, and drugs become the most viable option for survival. The connection between substance abuse and female criminality is incredibly strong (Bloom et al 2003), as is its connection to recidivism (Covington et al. 2007). The use of substances often intersects with many of the elements presented above. For example, drug abuse may come from more socially oriented problems associated with lack of empowerment, like financial strain and oppressive relationships. Gender sensitive addiction treatment looks at addiction like cancer- context plays 
an equally important role as biological disposition. Thus, treatment must take into account a woman's pathway and development, rather than treating all addictions the same (Covington 1998). Kissin et al (2013) conducted a study on gender sensitive drug abuse treatment which showed that women who completed the program were far less likely to commit drug related crimes as well as other crimes that could lead to rearrests. In a comparison of 13 programs, Kissin et al. created a scale of gender sensitivity based on the curriculum of the program and the environment it was completed in. The scale was indicative that the more gender responsive variables added into addiction treatment, like trauma, mental illness, relationships and empowerment, the lower the likelihood of reoffending.

Only in the recent years have studies been able to conclude that the incorporation of gender responsive factors are making a significant difference in women's lives (Kissin et al. 2013; Messina et al 2014; Bloom et al. 2003). This means the factors discussed above have been proven to be an effective method to rehabilitate the majority of women. Research has continued to indicate that women who have access to these programs are far more successful.

\section{Risk and Need Assessment: The Current Application}

Although on the road to change, risk tools continue to maintain a uniform application. Supporters of these risk assessments only now have begun to recognize gender as an important distinguisher for risk and need. Risk and need assessment tools have transformed dramatically in the last decade. Originally 
based on the simple management of prison misconduct, assessment tools now take into account post prison needs in order to understand recidivism risks. This means that those under community supervision, parole or probation, have their recidivism risk determined by an actuarial assessment. Because of this, these tools are the driving force behind policies directly effecting philosophy and program access in prisons (Salisbury et al. 2009). Whatever is deemed crucial within the risk assessment community is then used to funnel money into programs and other initiatives to reduce recidivism. According to the PEW center on the states,

Tools typically consist of a set of questions that guide face-to-face interviews with offenders, probing behaviors and attitudes that research shows are related to criminal reoffending...Responses are statistically weighted, based on research that shows how strongly each item correlates with recidivism. The tool then calculates an overall score that classifies and individual's risk of reoffending. " (Pew Center 2011)

The score of these assessments will determine what level of custody an inmate is placed in, low, medium or high. It also will determine what programs this individual needs (both inside, and post-release) to reduce their chance of reoffending. The first addresses the risks that the inmate brings to the institution, while the second refers to the needs that prisoner has in terms of context for criminal behavior, like substance abuse or mental health. The combination of both risk and need into one assessment is known as dynamic assessment (Andrews et al 2003). There are a few risk factors included in what is claimed to be a genderneutral assessment- the 'big four' are argued to be antisocial attitudes, peers, personality, and criminal history (Salisbury et al. 2009). All these categories apply 
to female offenders, but gender responsive literature points out the negligence of factors unique to women- such as trauma, relationships, motherhood, depression, self-esteem and victimization (Voohris et al. 2010; Reisig et al. 2006). Daly's pathways theory is a central part of this- showing the specific factors leading women into a criminal life. Using this theory, the differences between men and women become clear. Self-esteem, for example, is not included in these risk assessments. Empirical analysis has shown self-esteem to have a negative effect on preventing recidivism (Andrews et al. 2003). However, these studies are arbitrarily applied to women, without equal empirical standing (Bloom et al. 2006). Focusing on the factors that are proven to reduce recidivism, allows decisions to be made about risk levels. Those that are deemed 'high risk' are targeted to receive more resources because they are more likely to reoffend. These measures will concentrate resources on these individuals (Pew Center of the States, 2011).

The LSI-R (Levels of Service Inventory-Revised) is a dynamic risk assessment that is commonly used in correctional settings. This tool is based off of social learning theory, the idea that behavior is learned from social settings, and has 54 dichotomous variables meant to represent institutional risk and criminogenic needs. Combining the application of security level placement and recidivism risk analysis was meant to be a comprehensive way of distributing scarce resources (Andrews et al. 2006; Holtfreter et al. 2004). The empirical research done on the effectiveness on the LSI-R has been used to entitle it as a 'gender-neutral' assessment. At first, this claim was based on a majority of male 
studies. The small female offender population that was included was hardly representative of the majority (Holtfreter et al. 2004). Considering the importance that these assessments have on offenders lives in the last few years, an increasing number of researchers have sought to increase their validity by expanding the research to women. The application of this tool to women is generally seen as ineffective. Reisig et al. (2006) conducted a study on women under community supervision in Minnesota and Oregon to understand how accurately the LSI-R predicted recidivism. Kathleen Daly's pathways theory was used to frame the study. The results showed that women who followed economically motivated pathways to crime were accurately predicted by the LSI-R. For several reasons, economically motivated women are the exceptions to the rule that female recidivism rates are generally inaccurately predicted by "gender-neutral" assessments. First, they often come from a more advantaged place in society, coming from a higher economic status than the average woman. Secondly, they generally have not suffered from abuse and mental illness. They also do not have prior criminal histories or addiction behaviors.

The majority of female offenders, those with histories of trauma, mental illness, substance abuse and poverty, are not as accurately predicted by risk assessments. They therefore are often misclassified by the LSI-R. The consequences of misclassification of these women by the LSI-R are grim. Women who are placed in lower risk categories miss out on treatment and programs they desperately need, while those that are wrongly categorized as high risk are marginalized and it may aggravate their criminal behavior (Holfreter et al. 2007). 
While Reisig et al. showed the fault in the LSI-R, Salisbury et al. tested the theory that adding gender sensitive elements would increase the reliability and validity of the LSI-R assessment. This study compared different types of recidivism measures, as applied to women. Although the results were inconclusive from a recidivism prediction standpoint, there were many intersections in prediction of prison misconduct and community recidivism. In conclusion, although this study did not show a strong tie between all gender sensitive factors and recidivism, the inclusion of these factors helps create a full picture that can better understand misconduct within and after prison. Generally speaking, women do not recidivate nearly as often as men or present as much of a risk to their communities. Taking this into account, perhaps the current debate around female offenders should move away from predicting recidivism and instead to successfully facilitating transitions into communities, empowering them to have financial independence and healthy relationships with their children. (Voorhis et al. 2004; Salisnury et al. 2009) Turning focus onto encouraging autonomy will help keep children out of foster care, and give them a better chance at avoiding being incarcerated themselves. Prison programs focus on changing the act of criminal thinking, attempting to label individuals through tools like the LSI-R. However, studies have shown that although women need to be held responsible for their actions, if recidivism is to be prevented, state and social capital must support their recovery. Holfreter et al. (2004) conducted a study on the effectiveness of the LSI-R in predicting economically marginalized women's recidivism. What they found supported the literature faulting the LSI-R for its inability to apply to women. In 
their discussion they pointed out that although including poverty would increase validity of the LSI-R, it might also put women in restrictive programs that are detrimental to their recovery. The risk assessment atmosphere means a higher emphasis on supervision and control rather than access to social or state capital (Holtfreter et al. 2004). The male centered environment dictates strictness and supervision, while the female centered environment would in contrast benefit from a therapeutic environment (Bloom et al. 2003; Holtfreter et al. 2004). Focusing on the immediate economic needs of women as they try to reintegrate is far more likely to increase their chances of a successful transition.

Women and men present very different levels of risk due to not only the types of crime they commit, but their motivations. Women are far less likely to recidivate, but this doesn't mean they don't need resources (Deschenes et al. 2007). These risk levels that are universally applied must be reexamined, as they may be hindering the success of female offenders by placing them in categories that do not pertain to their needs.

\section{Implications for Further Study \& Policy}

Throughout this discussion, it has been seen that female offenders are not only different in action then their male offenders, but also in need. Most crimes committed by women are motivated by survival, whether that is economic, mental, or physical. Since assessments are being used to understand the allocation of prison resources, it is important to account for the diversity of needs in the 
prison population: Even if the assessment is decent at predicting accuracy, that isn't good enough. Gender specific literature shows that women have needs that are not being addressed-and studying these and applying them to risk assessment may help direct funding to appropriate programs. High rates of unnecessary recidivism put financial strain on states and their citizens, as well as damaging the immediate social ties of the woman. Dynamic risk assessment condenses the fate of a prisoner into one uniform report card. If we continue to use this, we must at least attempt to make it more inclusive. Gender specific knowledge and research must be applied to every level of correctional process- from conviction to release. This should help reduce female recidivism and relapse into addiction or unhealthy relationships. Tackling mental illness in prison, specifically for women, will help lower the number of homeless women on the street, and in prison. It's important to remember that making these changes requires extensive studies, which have only just begun (Voohris et al. 2010). By studying the needs of women we can establish an assessment tool that is efficient both fiscally and socially.

Women, more often than not, do not apply to the same risk levels as men. Misconduct observed in women who are classified as high-risk often resembles misconduct of men in medium or low security. What high risk means should be questioned, as should the purpose of the prison. Female offenders classified as "high risk" are misclassified because of the assessment's inability to diagnose mood disorders, or other needs specific to women. Understanding the purpose of prisons is pertinent in shaping this issue. Prisons are a place of rehabilitation, but also a place to hold those who are a danger to communities and themselves. 
Women prove to be less a danger to communities when they are released, and more a danger to themselves. It is crucial to include more addiction, and family resources to these women. In general, these risk levels need to be reassessed, because they are not universally applicable to not only women, but perhaps to trans people and men in prison. In the US department of Justice 2007 study on female recidivism, it was shown that 'risk' had to be defined within the context of the offender.

"The lower risk to public safety presented by female criminality was also confirmed in these analyses. These recidivism patterns point to a different type of risk for women than men. The risk represented by women, then, is not to public safety but instead is a risk for reincarceration."(Deschenes et al. 2007).

The biggest threat most women released from prison pose is upon them selves. They pose little threat on their community, making incarceration a waste of precious funding and resources. Using the evidence provided within this paper, it could be suggested that more money be budgeted in post release programs to prevent drug relapse and support mental health, the two biggest factor in female recidivism (Department of Justice 2007) these types of programs should be central to female risk assessments not as a classification for placement but as a guiding principle for programs. By making these needs a priority, more money could be placed in programs that follow women post release, since these seem to be more effective. It could also be suggested that welfare policy be taken under consideration. Immediate economic assistance after prison should help women, and their children, become productive members of society. Along side this 
suggested policy change, more research should be conducted around the idea of empowerment, including self-efficacy and financial autonomy. This is because although it is theoretically one of the most important needs for female offenders, its empirical validity is less apparent in the literature. In order to direct funding to the empowerment of female offenders, the evidence needs to be in place.

LIFT, or Living In Freedom Today, is a program founded by The Pathfinders of Oregon, a nonprofit devoted to creating rehabilitation programs in prisons. LIFT is a program that has begun to change its curriculum to incorporate gender sensitive needs. It would be suggested to study programs that have made shifts to better measure the application of gender sensitive risk assessment, as well as the success of community outreach programs. LIFT has started using trauma informed treatment for addiction, as well as empowering women to believe in themselves. Many of these women now attend colleges, such as Portland State University, and have avoided recidivism. Research could help show if this was due partly to the change in this programs philosophy.

Most importantly, but perhaps the hardest to grasp, is that the current state of risk and need assessments is not gender neutral. Because the disproportionate representation of male offenders has historically been the case there was little question that perhaps the foundation of actuarial assessments would not, in the future, apply to the mass numbers of incarcerated women. More and more researchers and feminist criminologists are taking this into account, and the direction must continue down this path. One cannot simply incorporate gender sensitive factors into these assessments, but rather begin restructuring from 
punishment to treatment, focusing on the realities of individual's lives. Using uniform assessments should be a supplementary tool that is validated for the demographic it will represent. The changing atmosphere around risk assessments shows a brighter future for the criminal justice system, and hopefully for women.

\section{References}

Agnew, Robert. "Foundation for a General Strain Theory of Crime and Delinquency." Criminology 30, no. 1 (February 1992): 47-87.

Allard, Patricia. "Life Sentences: Denying Welfare Benefits To Women Convicted Of Drug Offenses." The Sentencing Project, February 2002.

Andrews, D. A. "Risk Principle of Case Classification in Correctional Treatment: A MetaAnalytic Investigation." International Journal of Offender Therapy and Comparative Criminology 50, no. 1 (February 1, 2006): 88-100. doi:10.1177/0306624X05282556.

_ . "The Recent Past and Near Future of Risk And/or Need Assessment." Crime \& Delinquency 52, no. 1 (January 1, 2006): 7-27. doi:10.1177/0011128705281756.

Andrews, D.A., and Bonta, J. The Psychology of Criminal Conduct. 3rd ed. Cincinnati, OH, 2003.

Blanchette, Kelley, and Brown, Shelly. The Assessment and Treatment of Women Offenders: An Integrative Perspective. Chichester, UK: John Wiley \& Sons, 2006.

Bloom, Barbara, Owen, Barbara, and Covington, Stephanie. Gender-Responsive Strategies Research, Practice, and Guiding Principles for Women Offenders. National Insititute of Corrections, June 2003.

Brennan, Tim, Breitenbach, Markus, and Dieterich, William. Unraveling Women's Pathways to Serious Crime: New Findings and Links to Prior Feminst Pathways. Research Report. American Probation and Parole Association, 2010.

Broidy, L., and R. Agnew. "Gender and Crime: A General Strain Theory Perspective." Journal of Research in Crime and Delinquency 34, no. 3 (August 1, 1997): 275-306. doi:10.1177/0022427897034003001.

Bush-Baskette, Stephanie. "The War On Drugs and the Incarceration of Mothers." Journal of Drug Issues 30, no. 4 (2000): 919-28.

Dowden, C., and D. A. Andrews. "What Works for Female Offenders: A Meta-Analytic Review." Crime \& Delinquency 45, no. 4 (October 1, 1999): 438-52. doi: $10.1177 / 0011128799045004002$.

Greenfeild, Lawrence, and Snell, Tracy. Bureau of Justice Statistics Special Report: Women Offenders. U.S Department of Justice, December 1999.

Holtfreter, K., and R. Cupp. "Gender and Risk Assessment: The Empirical Status of the LSI-R for Women." Journal of Contemporary Criminal Justice 23, no. 4 (November 1, 2007): 363-82. doi:10.1177/1043986207309436. 
James, D., and Glaze, L. Mental Health Problems of Prison and Jail Inmates. Washington, D.C.: Bureau of Justice Statistics, 2006.

Jones, N. J., S. L. Brown, K. A. Wanamaker, and L. E. Greiner. "A Quantitative Exploration of Gendered Pathways to Crime in a Sample of Male and Female Juvenile Offenders." Feminist Criminology 9, no. 2 (April 1, 2014): 113-36. doi:10.1177/1557085113501850.

Kaplan, Alexandra. "The 'Self-in-Relation': Implications for Depression in Women." Psychotherapy: Theory, Research, Practice, Training 23, no. 2 (1986): 234-42. doi:10.1037/h0085603.

Kissin, Wendy, Tang, Zhiqun, Campbell, Keven, Claus, Ronald, and Orwin, Robert. "GenderSensitive Substance Abuse Treatment and Arrest Outcomes for Women." Journal Of Substance Abuse Treatment 46, no. 3 (March 2014): 332-39.

Mauer, Marc, Potler, Cathy, and Wolf, Richard. Gender and Justice: Women, Drugs, and Sentencing Policy. The Sentencing Project, November 1999.

Messina, Nena, Stacy Calhoun, and Jeremy Braithwaite. "Trauma-Informed Treatment Decreases Posttraumatic Stress Disorder Among Women Offenders." Journal of Trauma \& Dissociation 15, no. 1 (January 2014): 6-23. doi:10.1080/15299732.2013.818609.

Miller, JB. "Connections, Disconnections and Violations." In Work In Progress. Work In Progress 33. Wellesley, MA: Stone Center, 1990.

- Toward a New Psychology of Women. Boston: Beacon Press, 1976.

Pollack, Shoshana. "Reconceptualizing Women's Agency and Empowerment: Challenges to Self-Esteem Discourse and Women's Lawbreaking." Women \& Criminal Justice 12, no. 1 (October 12, 2000): 75-89. doi:10.1300/J012v12n01_05.

Reisig, Michael D., Kristy Holtfreter, and Merry Morash. "Assessing Recidivism Risk Across Female Pathways to Crime." Justice Quarterly 23, no. 3 (September 2006): 384-405. doi:10.1080/07418820600869152.

Richie, Beth. The Gendered Entrapment of Black Battered Women. New York: Psychology Press, 1996.

Salisbury, E. J., P. Van Voorhis, and G. V. Spiropoulos. "The Predictive Validity of a GenderResponsive Needs Assessment: An Exploratory Study." Crime \& Delinquency 55, no. 4 (October 1, 2009): 550-85. doi:10.1177/0011128707308102.

Siegel, Jane A., and Linda M. Williams. "The Relationship Between Child Sexual Abuse And Female Delinquency And Crime: A Prospective Study." Journal of Research in Crime and Delinquency 40, no. 1 (February 1, 2003): 71-94. doi:10.1177/0022427802239254.

Steffensmeier, Darrell, and Allan, Emilie. "Gender and Crime:Toward a Gendered Theory of Female Offending." Annual Reviews Inc. 22 (1996): 459-87.

Task Force on Federally Sentenced Women. "Creating Choices: The Report of the Task Force on Federally Sentenced Women." Ministry of the Solicitor General Canada, April 1990.

Van Voorhis, P., E. M. Wright, E. Salisbury, and A. Bauman. "Women's Risk Factors and Their Contributions to Existing Risk/Needs Assessment: The Current Status of a GenderResponsive Supplement." Criminal Justice and Behavior 37, no. 3 (March 1, 2010): 26188. doi:10.1177/0093854809357442.

White, Gale D. "Gender-Responsive Programs in U.S. Prisons: Implications for Change." Social Work in Public Health 27, no. 3 (March 29, 2012): 283-300. doi:10.1080/19371918.2012.629875.

Wright, E. M., E. J. Salisbury, and P. Van Voorhis. "Predicting the Prison Misconducts of Women Offenders: The Importance of Gender-Responsive Needs." Journal of Contemporary Criminal Justice 23, no. 4 (November 1, 2007): 310-40. doi:10.1177/1043986207309595. 
